\title{
Prediksi Harga Tutup Saham PT. Garuda Indonesia,Tbk Menggunakan Metode ARIMA
}

\author{
Johanes Lusikooya, Nelson Nainggolana*, Jullia Titaleya* \\ aJurusan Matematika, FMIPA, Unsrat, Manado
}

KATA KUNCI

Metode ARIMA, PT. Garuda

Indonesia.Tbk, Saham

\begin{abstract}
A B S T R A K
Tujuan dari penelitian ini adalah untuk menerapkan model ARIMA dalam memprediksi harga tutup saham PT. Garuda Indonesia,Tbk. 25 Oktober 2016 sampai 7 November 2016. Penelitian ini menggunakan data harga tutup saham PT. Garuda Indonesia,Tbk. Data yang digunakan yaitu data sekunder yang diambil dari website perusahaan PT. Garuda Indonesia,Tbk. sejak 1 Januari 2013 sampai 24 Oktober 2016.Dari hasil penelitian menunjukkan bahwa data 1 Januari 2013 sampai 24 oktober 2016 dapat digunakan untuk memprediksi harga tutup saham 25 oktober 2016 sampai dengan 7 November 2016. Hasilnya model ARIMA untuk harga tutup saham adalah ARIMA $(3,1,3)$ yang dapat digunakan untuk memprediksi data 25 oktober 2016 sampai dengan 7 November 2016
\end{abstract}

KEYW OR D S

ARIMA method, PT. Garuda Indonesia, Tbk, Stock
TERSEDIA ONLINE

1 Februari 2017

\section{Pendahuluan}

Pesatnya kemajuan ekonomi yang semakin modern membuat kebanyakan orang mulai berpikir untuk mendapatkan keuntungan dalam dunia investasi. Berbicara mengenai investasi, salah satu yang paling menarik dalam dunia investasi sekarang ini yaitu saham. Informasi tentang harga saham adalah salah satu hal yang dapat mempengaruhi aktifitas perdagangan di pasar modal. Dalam memprediksi harga saham biasanya para investor menggunakan data time series, yang tergolong sederhana yaitu model Moving Average. Model MA (Moving Average) yaitu model yang melihat pergerakan variabel melalui residualnya di masa lalu. (Arsyad, 1995). Di Indonesia sendiri punya banyak perusahaan yang mempunyai harga saham yang baik, dalam karya tulis ini diambil PT. Garuda
Indonesia dimana harga sahamnya yang naik turun dalam kurun waktu dua tahun yakni 2011-2013. Dalam penelitian ini diambil sampel yaitu PT. Garuda Indonesia, Tbk pada bulan Oktober 2016 menggunakan data harga saham pada periode sebelumnya dari tahun 2013 sampai 2016.

\section{Material dan Metode \\ 4.1 ARIMA (Autoregressive Integrated Moving Average) \\ Metode Autoregressive Integrated Moving Average (ARIMA) biasa disebut juga sebagai metode Box-Jenkins merupakan metode yang secara intensif di kembangkan oleh George Box dan Gwilym Jenkins pada tahun 1970 (Iriawan N dan Astuti P, 2006). Yang termasuk dalam model time series ini yaitu : Autoregressive, Moving Average, Autoregressive}


Moving Average, dan Autoregressive Integrated Moving Average

2.2 Model Autoregresif (Autoregressive,AR)

Model Autoregresif adalah model yang menyatakan bahwa data pada periode sekarang dipengaruhi oleh data pada periode sebelumnya.Model Autoregresif dengan ordo $p$ disingkat dengan ARIMA $(p, 0,0)$. Bentuk umum dari model ini sebagai berikut (Mulyono, 2000) :

$$
\begin{aligned}
& Z_{t}=\mu+\phi_{1} Z_{t-1}+\phi_{2} Z_{t-2}+\cdots+\phi_{p} Z_{t-p}+ \\
& e_{t}
\end{aligned}
$$

\subsection{Model MA (Moving Average)}

Model Moving Average menyatakan hubungan antara nilai pengamatan dari kesalahan peramalan sekarang dan masa lalu yang berurutan, persamaan itu dinamakan moving average model. Model moving average dengan orde $q$ disingkat $M A(q)$ atau $\operatorname{ARIMA}(0,0, q)$. Bentuk umum dari model ini adalah sebagai berikut (Mulyono, 2000) :

$$
Z_{\mathrm{t}}=\mu+e_{\mathrm{t}}-\theta_{1} e_{\mathrm{t}-1}-\theta_{2} e_{\mathrm{t}-2}-\cdots-\theta_{\mathrm{p}} e_{\mathrm{t}-\mathrm{p}}
$$

Dimana :

$\mu \quad$ : Konstatnta

$\theta_{1}, \theta_{2}, \theta_{\mathrm{p}}:$ Koefisien parameter moving average keet $\quad$ : Sisaan pada saat ke-t

\subsection{Model ARMA (Autoregressive Moving average)}

Model ARMA (Autoregressive Moving average) ialah gabungan dari model $\operatorname{AR}(p)$ dan $\mathrm{MA}(q)$ sehingga memiliki asumsi bahwa data periode sekarang dipengaruhi oleh data periode lampaunya dan nilai lampau kesalahannya.

Model ARMA dengan orde $p$ dan $q$ ditulis $\operatorname{ARMA}(p, q)$ atau ARIMA $(p, 0, q)$. Bentuk umum dari model ini adalah sebagai berikut (Mulyono,2000) :

$$
\begin{aligned}
& \mathrm{Z}_{\mathrm{t}}=\mu+\phi_{1} \mathrm{Z}_{\mathrm{t}-1}+\phi_{2} \mathrm{Z}_{\mathrm{t}-2}+\cdots+\phi_{\mathrm{p}} \mathrm{Z}_{\mathrm{t}-\mathrm{p}}+ \\
& \mathrm{e}_{\mathrm{t}}-\theta_{1} \mathrm{e}_{\mathrm{t}-1}-\theta_{2} \mathrm{e}_{\mathrm{t}-2}-\cdots-\theta_{\mathrm{q}} \mathrm{e}_{\mathrm{t}-\mathrm{q}}
\end{aligned}
$$

\subsection{Model ARIMA (Autoregressive Integrated Moving Average)}

Model Arima merupakan model time series yang digunakan berdasarkan asumsi bahwa data time series bersifat stasioner artinya rata-rata dan varian suatu data time series konstan.(Mulyana,2004)

$$
\begin{aligned}
& Z_{t}-Z_{t-1}=\phi_{1}\left(Z_{t-1}-Z_{t-2}\right)+ \\
& \phi_{2}\left(Z_{t-2}-Z_{t-3}\right)+\cdots+\phi_{p}\left(Z_{t-p}-\right. \\
& Z_{t-p-1)}+e_{t}-\theta_{1} e_{t-1}-\cdots-\theta_{q} e_{t-q}
\end{aligned}
$$

\subsection{Stasioneritas}

Stasioneritas berarti bahwa tidak adanya perubahan drastis pada data. Fluktuasi pada data tersebut biasanya berada disekitar suatu nilai ratarata yang konstan, tidak tergantung pada waktu dari fluktuasi tersebut. Data Time Series dikatakan stasioner jika rata-rata dan variannya konstan. (Makridakis,1999). Apabila data yang menjadi input dari model ARIMA tidak stasioner, perlu dilakukan modifikasi agar dapat menghasilkan data yang stasioner, kondisi seperti ini dapat diatasi dengan proses selisih (Differencing). (Mulyono,2000).

\subsection{Proses Selisih (Differencing)}

Proses selisih dilakukan jika data tidak stasioner dalam rata-ratanya. Salah satu cara umum yang dipakai adalah metode pembedahan atau lebih dikenal dengan sebutan differencing, yaitu mengurangi nilai data pada suatu periode dengan nilai data pada periode sebelumnya, yang dapat ditulis sebagai berikut ( Aritonang 2002) :

$$
W_{t}=Z_{t}-Z_{t-1}
$$

\subsection{Fungsi Autokorelasi (Autocorrelation function,ACF)}

Dengan menggukan fungsi autokorelasi pengujian terhadap kestasioneran data dapat dilakukan, fungsi autokorelasi sendiri merupakan fungsi yang menunjukkan besarnya korelasi antara pengamatan pada waktu ke t dengan pengamatan pada waktu sebelumnya (Suyono,2005).

Secara matematis rumus koefisien autokorelasi adalah (Makridakis,1999) :

$$
\rho_{k}=\frac{\sum_{\mathrm{t}=1}^{\mathrm{n}-\mathrm{k}}(X-X)\left(X_{\mathrm{t}+\mathrm{k}}-X\right)}{\sum_{\mathrm{t}=1}^{\mathrm{n}}\left(X_{\mathrm{t}}-X\right)^{2}}
$$

Dimana :

$$
\begin{aligned}
& \rho_{k}: \text { Koefisien Korelasi } \\
& \bar{X} \text { : Rata-rata Observasi }
\end{aligned}
$$

\subsection{Fungsi Autokorelasi Parsial (Partial Autocorrelation function,PACF)}

Autokorelasi Parsial digunakan untuk mengukur tingkat keeratan antara $X_{t}$ dan $X_{t-k}$ apabila pengaruh dari lag $1,2,3, \ldots$ dan seterusnya sampai k-1 dianggap terpisah. Hubungan antara autokorelasi parsial dengan lag-nya disebut fungsi autokorelasi parsial. Menurut Wei (1990), rumus fungsi autokorelasi parsial dapat ditulis dengan :

$$
\phi_{k+1, k+1}=\frac{\rho_{k+1}-\sum_{j=1}^{k-1} \phi_{k j \rho_{k+1}-j}}{1-\sum_{j=1}^{k-1} \phi_{k j \rho_{j}}}
$$

\subsection{Metode Penelitian}

Data yang digunakan untuk penelitian ini adalah data sekunder. Data berupa nilai harga tutup saham harian PT Garuda Indonesia, Tbk yang diperoleh dari Yahoo Finance. Suatu model time series dikatakan baik apabila telah sesuai dengan kenyataan. Dengan kata lain, apabila kesalahan (error) model semakin kecil, maka model bisa 
dikatakan baik (Iriawan dan Astuti,2006). Analisis Data dilakukan secara berturut-turut adalah :

1. Pengambilan Data

2. Plot Data

3. Pemeriksaan Kestasioneran Data

4. Identifikasi Model Arima

5. Penentuan Parameter $p, d$ dan $q$ dalam ARIMA

6. Penentuan persamaan model ARIMA

7. Validasi Prediksi

8. Prediksi

\section{Hasil dan Pembahasan}

Data harga tutup saham harian PT.Garuda Indonesia,Tbk. Dilakukan melalui plot deret waktu untuk periode 1 Januari 2013 sampai dengan 24 Oktober 2016 selama 988 hari

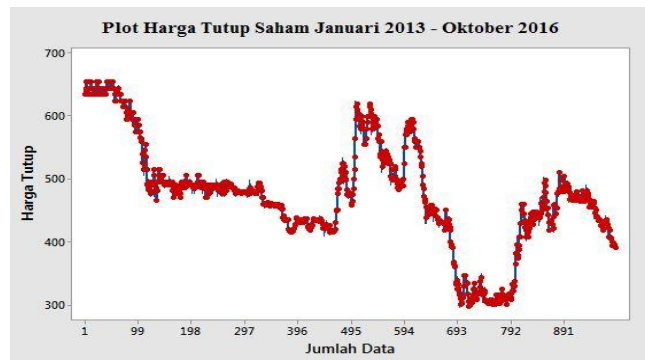

Gambar 1. Plot data harga tutup saham harian PT.Garuda Indonesia,Tbk. 1 Januari 2013 sampai 24 Oktober 2016

Pada gambar 1 terlihat data harga tutup saham harian periode 1 januari 2013 sampai dengan 24 oktober 2016 menujukan nilai harga saham yang berubah-ubah, oleh karena itu dapat dikatakan bahwa data pada periode penelitian ini belum stasioner. Data yang tidak stasioner perlu dilakukan proses differencing agar menjadi data yang bersifat stasioner.

Karena data ini belum stasioner maka belum bisa diproses menggunakan ARIMA oleh karena perlu dilakukan proses pembedahan (Differencing).

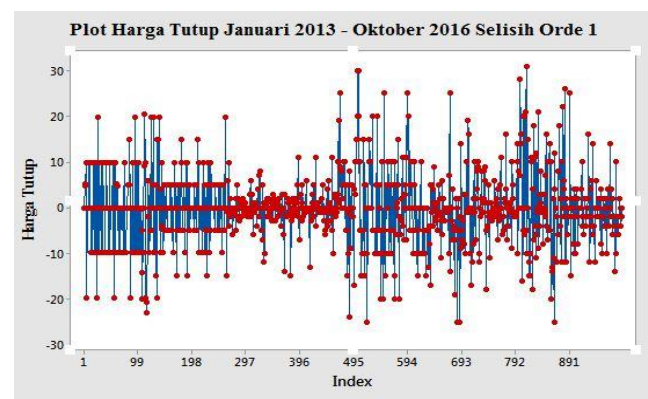

Gambar 2. Plot Data Harga Tutup Saham Harian PT. Garuda Indonesia,Tbk. 1 Januari 2013 - 24 Oktober 2016 Dengan Selisih Orde 1

Pada Gambar 4. Data PT. Garuda Indonesia,Tbk. diatas terlihat bahwa data bergerak disekitar rata-rata dan telah melalui proses pembedaan tingkat 1 , dari data tersebut dapat diamati bahwa data sudah bersifat stasioner. Proses pembedaan (Differencing) yang telah dilakukan mengidentifikasi bahwa nilai d yang bisa dipakai ialah $\mathrm{d}=1$

Tabel 1. Penentuan Nilai AR(p), I(d), MA(q) Dengan MSE untuk data harga tutup saham harian PT.Garuda Indonesia,Tbk 1 Januari 2013 sampai 24 Oktober 2016

\begin{tabular}{|c|c|}
\hline \multicolumn{2}{|c|}{ Selisin 1 (d=1) } \\
\hline Parameter & Nilai MSE \\
\hline$(1,1,0)$ & 63,9 \\
\hline$(1,1,1)$ & 63,8 \\
\hline$(1,1,2)$ & 63,9 \\
\hline$(1,1,3)$ & 63,9 \\
\hline$(2,1,0)$ & 63,8 \\
\hline$(2,1,1)$ & 63,9 \\
\hline$(2,1,2)$ & 63,9 \\
\hline$(2,1,3)$ & 63,9 \\
\hline$(3,1,0)$ & 63,9 \\
\hline$(3,1,1)$ & 63,9 \\
\hline$(3,1,2)$ & 64,0 \\
\hline$(3,1,3)$ & 63,7 \\
\hline
\end{tabular}

Dari tabel 1 terdapat 12 model yang di differensing satu kali yang digunakan untuk memprediksi harga tutup saham dengan data tahun 2013 sampai Oktober 2016, berdasarkan teori semakin kecil nilai MSE yang dihasilkan suatu model maka model semakin baik. Sehingga diketahui bahwa parameter $p=3, d=1, q=3$ atau ARIMA $(3,1,3)$ dengan hasil nilai MSE terkecil yaitu 63,7 dan dapat digunakan untuk memprediksi harga tutup saham PT. Garuda Indonesi,Tbk 25 oktober 2016 sampai dengan 7 November 2016.

\section{Menentukan Persamaan ARIMA (p,d,q) Pada Data Harga Tutup Saham Harian Maksimum PT. Garuda Indonesia,Tbk Tahun 2013 sampai 2016}

Berdasarkan hasil penentuan parameter diperoleh ARIMA $(3,1,3)$ pada Tabel 1, dengan Koefisiennya yaitu AR 1: 0,3769, AR 2: -0,6774, AR 3: 0,7224, MA 1: 0,3066, MA 2 : -0,6954, MA 3 : 0,6854 Konstanta: -0,1428, dibuat analisis persamaan ARIMA $(3,1,3)$ menjadi :

$$
\begin{aligned}
& Z_{t}=-0,1428+1,3769 Z_{t-1}-1,0543 Z_{t-2}+ \\
& 1,3998 Z_{t-1}-0,7224 Z_{t-4}-0,3066 e_{t-1}+ \\
& 0,6954 e_{t-2}-0,6854 e_{t-1}
\end{aligned}
$$


3. Kesimpulan

Model untuk memprediksi Harga tutup saham pada 25 Oktober 2016 sampai 7 November 2016 diperoleh yaitu ARIMA $(3,1,3)$ dengan persamaan :

$$
\begin{aligned}
& Z_{\mathrm{t}}=-0,1428+1,3769 Z_{\mathrm{t}-1}-1,0543 Z_{\mathrm{t}-2}+ \\
& 1,3998 Z_{\mathrm{t}-\mathrm{a}}-0,7224 Z_{\mathrm{t}-4}-0,3066 e_{\mathrm{t}-1}+ \\
& 0,6954 e_{\mathrm{t}-2}-0,6854 e_{\mathrm{t}-\mathrm{a}}
\end{aligned}
$$

Tabel 2 Harga prediksi saham harian PT. Garuda Indonesia untuk 25 Oktober sampai dengan 7 November 2016 berturut - turut

\begin{tabular}{|l|c|}
\hline Tanggal & Harga (Rp) \\
\hline $25 / 10 / 2016$ & 388,6832 \\
\hline $26 / 10 / 2016$ & 380,6728 \\
\hline $27 / 10 / 2016$ & 391,922 \\
\hline $28 / 10 / 2016$ & 361,438 \\
\hline $31 / 10 / 2016$ & 395,6252 \\
\hline $1 / 11 / 2016$ & 347,1919 \\
\hline $2 / 11 / 2016$ & 400,1392 \\
\hline $3 / 11 / 2016$ & 318,4017 \\
\hline $4 / 11 / 2016$ & 395,6983 \\
\hline $7 / 11 / 2016$ & 299,0026 \\
\hline
\end{tabular}

Daftar Pustaka

Arsyad, L.1995. Peramalan Bisnis. Ghalia Indonesia, Jakarta.

Iriawan N dan S.P, Astuti. 2006. Mengolah Data Statistik dengan Mudah MINITAB 14.Yogyakarta: Penerbit Andi. Suyono. 2005. Diktat Mata Kuliah Analisis Runtun Waktu. Jurusan matematika FMIPA UNJ: Jakarta.

Mulyana.2004. Buku Ajar Analisis Deret Waktu. Bandung: FMIPA Universitas Padjadjaran.

Mulyono. 2000. Buku Ajar Analisis Deret Waktu. Bandung: FMIPA Universitas Padjadjaran

Wei,W.W.S.1990. Time Series Analysis: Univariate and Multivariate Methods. Publishing Company, USA 